\title{
Association of goal orientation with work engagement and burnout in emergency nurses
}

\author{
Jef Adriaenssens ${ }^{1}$, Veronique De Gucht ${ }^{1}$ and Stan MaEs ${ }^{2}$ \\ ${ }^{1}$ Leiden University, Institute of Psychology, Health Psychology Unit, The Netherlands and ${ }^{2}$ Leiden University, \\ Institute of Psychology and Leiden University Medical Center, Health and Medical Psychology, The Netherlands
}

\begin{abstract}
Association of goal orientation with work engagement and burnout in emergency nurses: Jef Adriaenssens, et al. Leiden University, Institute of Psychology, Health Psychology Unit, The Netherlands-Objectives: Goal orientation is a mindset towards the achievement of work-related goals, and it has been found to be related to occupational well-being. This study explored to what extent the 4-dimensional model of goal orientation adds additional variance to the explanation of burnout and work engagement in emergency nurses, after controlling for demographics, job characteristics and organizational variables. Methods: Self-report questionnaires including the Leiden Quality of Work Questionnaire for Nurses, Goal Orientation Questionnaire, Maslach Burnout Inventory and Utrecht Work Engagement Scale were completed by 170 out of 274 emergency nurses from 13 secondary Belgian hospitals (response rate $62 \%$ ). Hierarchical multiple regression analyses were conducted. Results: Goal orientation explained 14 and $13 \%$ of the variance in burnout and work engagement respectively. Job control was predictive of both outcomes. Job demands was a predictor of burnout, and social support predicted work engagement. Reward was related to work engagement. The mastery-approach goal orientation was strongly related to an increase in work engagement and to a decrease in burnout. The performance-avoidance goal orientation was strongly related to a decrease in work engagement and to an increase in burnout. The performance-approach and mastery-avoidance goal orientations were not predictive for the two outcome variables. Conclusions: Goal orientation explains additional variance in burnout and work engagement over and above work characteristics and organizational variables. A mastery-approach goal orientation appears to be beneficial while a performance-avoidance goal orientation is not. Hospital management should therefore invest in personal involvement and growth of ER-
\end{abstract}

Received Apr 4, 2014; Accepted Dec 1, 2014

Published online in J-STAGE Jan 20, 2015

Correspondence to: J. Adriaenssens, Institute of Psychology, Health Psychology Unit, Leiden University, PO Box 9555, 2300 RB Leiden, The Netherlands (e-mail: j.adriaenssens@umail.leidenuniv.nl) nurses and in a rewarding organizational culture. (J Occup Health 2015; 57: 151-160)

Key words: Burnout, Emergency nurses, Goal orientation, Occupational health, Work engagement

A lot of studies have explored the determinants of occupational stress and burnout in emergency (ER) nurses. Among these determinants are demographic characteristics (e.g., age, gender), personality characteristics (e.g., lack of hardiness), coping strategies (e.g., avoidant behavior), repeated exposure to traumatic events, work characteristics (e.g., high job demand, low job control \& low social support) and organizational factors (e.g., lack of communication, collaboration and resources, bad organizational culture) $)^{1,2)}$. Far less research has, however, been conducted from a more positive perspective, e.g. exploring the determinants of work engagement. While job characteristics have been proven to predict work engagement ${ }^{1}$, motivational aspects are also thought to play an important role. Research has shown that low levels of intrinsic motivation are associated with lower levels of work engagement and high levels of burnout ${ }^{3,4)}$. Goal orientation is an important motivational concept based upon the difference between intrinsic and extrinsic motivation and can be defined as a mindset towards the achievement of work-related goals ${ }^{5)}$. A mastery goal orientation, implying striving for growth, has been found to be strongly associated with intrinsic motivation $^{6}$, in contrast to a performance avoidant goal orientation or failure avoidance ${ }^{7}$. Several studies have shown that striving for competence (mastery goal orientation) is positively associated with work engagement and negatively associated with burnout, while striving to demonstrate competence (performance goal orientation) or avoiding effort (work avoidance goals) were shown to have a negative association with work or task engagement and a positive association with burnout ${ }^{7-10)}$. These studies have, however, been conducted in teachers and learning contexts, and to 
our knowledge, there is to date no research on the influence of goal orientation on work engagement and burnout in health professionals.

\section{Theoretical framework}

The main dimensions of the concept of goal orientation $^{11)}$ are "mastery" and "performance". A mastery goal orientation indicates a persons striving to develop skills and competencies, learn, understand and internalize information ${ }^{11)}$. Individuals with a mastery goal orientation tend to strive for personal development and growth, resulting in achievement-related behavior and task engagement. A mastery goal orientation is associated with more resilience to increases in workload ${ }^{12)}$, more creativity ${ }^{13)}$, more effort and persistence in tasks and more resistance to obstacles and problems, because tasks are perceived as a challenge and not as a threat. Employees with a mastery goal orientation are found to have a strong intrinsic motivation ${ }^{14)}$, are known to adapt easier to change ${ }^{15)}$ and are more oriented to cooperation with peers as a necessary element for succeeding. Because failure is not a primordial concern, they perceive less stress, and their performance will improve. Moreover, a mastery goal orientation is related to higher self-efficacy, positive coping, and higher levels of well-being ${ }^{16)}$.

A performance goal orientation indicates a persons' striving to demonstrate competence, i.e., focusing on the impression that others have of their abilities, attempting to create an image of high ability and avoiding activities that could damage that image ${ }^{11)}$. Employees with a performance goal orientation have more problems with adjustment to changes at work, feel happier with tasks they have rehearsed extensively ${ }^{17)}$ and experience a rise in anxiety when they feel judged or evaluated. They usually are not oriented towards cooperation and seek less help and support from others ${ }^{18)}$. Because of their "aversion" to sharing and collaboration, they tend more often to demonstrate superiority than to work towards integration of competing values and interests ${ }^{19}$. A performance orientation leads to higher levels of interpersonal conflict with peers and supervisors and to less exchange of knowledge on the work floor ${ }^{13)}$, because peers and supervisors are perceived as a threat rather than as a safe source of knowledge and experience.

In the late 1990s, Elliot stated that one also had to make a distinction in the performance dimension between approach and avoidance ${ }^{20)}$. An approach orientation (promotion focused) is a proactive attempt to achieve success, while an avoidance orientation (prevention focused) is an attempt to evade a situation because of a focus on failure ${ }^{16)}$. Elliot and colleagues proposed to define performance approach and performance avoidance as two distinct dimensions ${ }^{20)}$.
Performance-approach (PAp) orientation is defined as the desire to prove one's competence and to gain favorable judgments about $\mathrm{it}^{21)}$. It has been found to be related to persistence and positive affect but also to anxiety, disruptive behavior and low retention of knowledge $^{16)}$. Performance-avoidance (PAv) orientation is defined as the desire to avoid disapprovement of one's competence and to avoid negative judgments about $\mathrm{it}^{21)}$. It has been found to be related to low efficacy and anxiety ${ }^{16}$. In recent years, researchers have argued that there is enough evidence to also divide the mastery goal orientation into approach and avoidance dimensions $^{22}$. Mastery-avoidance (MAv) orientation is defined as "a focus on avoiding self-referential or task-referential incompetence" (striving to avoid loss of skills, abilities and knowledge or misunderstand material), whereas mastery-approach (Map) orientation is defined as striving to develop one's skills and abilities, advance one's learning, understand material, or master a task ${ }^{23)}$. The final theoretical model, consisting of the four dimensions of goal orientation, is named "the $2 \times 2$ goal orientation framework" 22 .

The definition of job characteristics, as used in the present study, is based on the Job Demand Control Support (JDCS) model ${ }^{24)}$. In this model, psychological strain and ill health are predicted by a combination of high job demands, low job control and low social support at work from a supervisor and/or colleagues. The JDCS model has been shown to explain an important part of the variance in stresshealth outcomes ${ }^{25)}$.

The organizational variables used in the present study are derived from the Tripod accident causation model $^{26)}$ which postulates that work-related states of mind (e.g., expectations, motives, plans, haste) can be generated by dysfunctional aspects of the organizational environment or latent failures (e.g., lack of work agreements, unclarity of procedures, imbalanced reward system, lack of personnel resources, lack of material resources and social harassment). These organizational variables were found to be related to stress-health outcomes in ER nurses ${ }^{1)}$.

Burnout can be defined as a psychological state of depletion of social and personal resources, resulting from prolonged emotional or psychological stress on the job. The concept has three dimensions: emotional exhaustion, depersonalization and lack of personal accomplishment ${ }^{27)}$. Work engagement describes the way workers experience their work and can be defined as "...a positive, fulfilling, work-related state of mind that is characterized by vigor, dedication, and absorption"28).

Research in nurses has shown a relationship between goal orientation and occupational well-being. In a study in nurse managers, self-efficacy was posi- 
tively related to a mastery goal orientation and performance-approach orientation ${ }^{5}$. Another study revealed that the negative impact of staff shortage, high physical demands, poor work agreements and lack of skill discretion in nurses with a prevention focus was bigger than in promotion focused nurses ${ }^{29}$.

The main research question of the present study was to what extent does the four dimensional model of goal orientation add additional variance to the explanation of work engagement and burnout in ER nurses after controlling for job characteristics and organizational variables?. More specifically, it is hypothesized that (1) a mastery-approach goal orientation is related to higher levels of work engagement and lower levels of burnout, (2) a performanceapproach goal orientation is related to lower levels of work engagement and higher levels of burnout, (3) a mastery-avoidance goal orientation is related to lower levels of work engagement and higher levels of burnout, and (4) a performance-avoidance goal orientation is related to lower levels of work engagement and higher levels of burnout.

\section{Subjects and Methods}

\section{Study design and participants}

This cross-sectional survey was conducted in the emergency departments of 13 Belgian general hospitals, by means of a self-administered structured questionnaire from April 2009 to July 2009. Thirteen hospitals were selected at random from all over Flanders. Every respondent, working in the ER departments of these hospitals, received an invitational letter, with information on the study, and an informed consent form. The first author, an ER nurse, visited every emergency department and provided information on the objectives and the relevance of the study. Afterwards, the head nurse distributed the paper questionnaire randomly to the ER nurses. Each respondent was asked to fill in the questionnaire individually in his/her leisure time. One reminder was sent one month after the start of data collection. The completed questionnaires could be deposited anonymously in a sealed mailbox in the respondents' emergency departments. The mailboxes were collected by the first author three months after the distribution of the questionnaires. The eligible population consisted of all the ER Nurses who had patient contact $(n=274)$ and had worked at least six months in an emergency care unit. Head nurses and nursing managers were excluded from the sample. A total of 170 completed questionnaires were returned (response rate $62.0 \%$ ).

\section{Measures}

1) Predictors

\section{Personal characteristics}

In the present study, age, gender, level of education, type of shift work (with/without night shifts) and job time (part time/full time) were taken into account as personal characteristics.

Job characteristics and organizational variables

The Leiden Quality of Work Questionnaire for Nurses (LQWQ-N) ${ }^{30)}$ was used to assess job characteristics as a measure for quality of work. The LQWQ-N consists of 15 subscales measuring job characteristics (6 dimensions), and organizational variables (7 dimensions), and two outcome variables ("job satisfaction" and "turnover intention"). The items of the LQWQ-N are occupation specific. The development of the LQWQ-N was partly based on the Job Content Questionnaire (JCQ) ${ }^{30,31)}$. The JDCS concepts are thus measured in a similar way. The factor structure of the LQWQ-N was determined by means of factor analyses and reliability analyses. All items are formulated as statements that have to be rated on a 4-point Likert scale, ranging from "totally disagree" to "totally agree". For the purpose of this study, the subscales described below were used. For each scale, the Cronbach's $\alpha$ for this sample is given, as well as the number of items.

Job characteristics: The job characteristics dimensions consisted of work and time demands $(\alpha=0.76$; 5 items; work pressure and time pressure); physical demands ( $\alpha=0.74 ; 4$ items; physical burden of work; skill discretion $(\alpha=0.82 ; 4$ items; task variety and the extent to which the job challenges one's skills); decision authority ( $\alpha=0.73$; 4 items; extent to which nurses have the freedom to act on what they know and the amount of decision authority they have over their work conditions); social support supervisor ( $\alpha=0.93 ; 4$ items; support provided by the supervisor), and social support colleagues ( $\alpha=0.83 ; 4$ items; support provided by colleagues). For the purpose of this study and in accordance with the LQWQ-N guidelines, the sum score for the dimensions work and time demands and physical demands was used as a measure of job demands $(\alpha=0.73 ; 9$ items). The sum score of the dimensions skill discretion and decision authority was used as a measure of job control ( $\alpha=0.82 ; 8$ items). The sum score for social support supervisor and social support colleagues was used as a global measure of social support ( $\alpha=0.87 ; 8$ items).

Organizational variables: The organizational variables dimensions consisted of nurse-doctor collaboration $(\alpha=0.56 ; 4$ items; jointly sharing information for decision making and problem solving); rewards ( $\alpha=0.71 ; 6$ items; rewards in terms of bonuses or appreciation); personnel resources $(\alpha=0.68 ; 4$ items; 
amount and quality of personnel on a particular ward); material resources ( $\alpha=0.77 ; 3$ items; availability and quality of materials and instruments on a particular ward); work agreements ( $\alpha=0.79 ; 4$ items; quality and feasibility of procedures); internal communication $(\alpha=0.59 ; 5$ items; communication between departments, information provision); social harassment $(\alpha=0.86 ; 4$ items; use of peer rejection or exclusion to humiliate or isolate a person). Because of the low Cronbach $\alpha$ score, the dimensions internal communication, nurse-doctor collaboration and personal resources were excluded from further analysis.

\section{Goal orientation}

This study used the Dutch version of an 18-item measure for assessment of the four-factor structure of goal orientation, based on research by Vandewalle ${ }^{21)}$ and Baranik, Barron, and Finney ${ }^{22}$. The scale was found to be reliable and valid in previous research ${ }^{22}$. An exploratory factor analysis was conducted using principal components analysis with varimax rotation (eigenvalue $\geq 1$ ). This analysis revealed a four-factor solution, which accounted for $54.2 \%$ of the total variance. Two items did not load sufficiently on the correct factor and were therefore omitted. The final instrument used for the present study consisted of 4 subscales: mastery-avoidance (MAv) ( $\alpha=0.71 ; 5$ items; focus on avoiding self-referential or task-referential incompetence); mastery-approach (MAp) ( $\alpha=0.69$; 3 items; striving to develop one's skills and abilities, advance one's learning, understand material, or master a task); performance-approach (PAp) $(\alpha=0.75$; 4 items; the desire to prove one's competence and to gain favorable judgments about it), and PerformanceAvoidance (PAv) $(\alpha=0.72 ; 4$ items; the desire to avoid disapproval of one's competence and to avoid negative judgments about it). All items are formulated as statements that have to be rated on a 6-point Likert scale, ranging from "strongly agree" to "strongly disagree".

\section{2) Outcome variables}

Burnout was assessed by means of the 20-item Dutch version of the Maslach Burnout Inventory for Human Services Survey (MBI-HSS) ${ }^{32)}$. The MBI-HSS consists of three dimensions: emotional exhaustion (EE) ( $\alpha=0.85 ; 8$ items), depersonalization (DP) ( $\alpha=0.71$; 5 items), and lack of personal accomplishment (PA) $(\alpha=0.80 ; 7$ items). Items are scored on a 7-point Likert scale ranging from 0 (never) to 6 (always). The total score for burnout was calculated by use of a weighted sum score of the three dimensions $(0.4 \times \mathrm{EE}+0.3 \times \mathrm{DP}+0.3 \times \text { inversed-PA })^{33)}$. For the purpose of this study, only the sum score was used as a global measure of burnout ( $\alpha=0.72 ; 20$ items). A high score is indicative of burnout. The MBI-HSS was found to have adequate internal consistency, reliability and validity ${ }^{34)}$.

Work engagement was assessed by means of the short version of the Utrecht Work Engagement Scale $(\mathrm{UWES})^{35)}$. The items of the UWES are grouped into three subscales: vigor $(\alpha=0.88 ; 3$ items); dedication ( $\alpha=0.88 ; 3$ items), and absorption ( $\alpha=0.86 ; 3$ items). The total score for work engagement was calculated by use of the sum score of the subscales $(\alpha=0.95 ; 9$ items). For the purpose of this study, only the sum score was used as a measure of work engagement. All items were scored on a 7-point rating scale, ranging from 0 (never) to 6 (daily). A higher score is indicative of a higher work engagement. The UWES was found to have adequate consistency, reliability and validity ${ }^{36)}$.

\section{Ethical considerations}

Every potential respondent received an invitational letter, containing information on the study and an informed consent letter. These informed consent letters were signed by each respondent and collected before data collection. Confidentiality was guaranteed to all participants by use of an identification code for every questionnaire. Only one of the researchers had access to the identification list. Participation was on a voluntary base. Appropriate institutional board approval was obtained for this study. In Belgium, approval from the board of participating hospitals is required, and was granted by all participating hospitals.

\section{Data analysis}

For the present study, the Statistical Package for the Social Sciences for Windows 20.0 (IBM, Armonk, NY, USA), was used to analyze the data. Descriptive statistics (means, standard deviations, frequency distributions, skewness and kurtosis) were computed. Pearson correlations were calculated and one-way ANOVA and independent sample-t tests were performed for analysis of predictors and outcomes. Hierarchical regression analyses were conducted to estimate the strength of the association between demographic characteristics (block 1), job characteristics (block 2), organizational variables (block 3) and goal orientation (block 4) as predictors and burnout and work engagement as outcomes. A $p$-value of 0.05 or lower was considered statistically significant.

\section{Results}

\section{Personal characteristics (Table 1)}

The majority of the ER nurses were female (58.8\%). The mean age of the respondents was 38.45 years (SD 9.18). More than $85 \%$ of the ER nurses had a bachelor's degree and $82 \%$ were holders of Certified 
Emergency Nurse' (CEN) certification. The mean job experience as an ER nurse was 12.07 years (SD 7.99). Almost $59 \%$ of the ER nurses worked full time (38 h/week), and $87.3 \%$ worked changing shifts, including night shifts. Female gender was related to higher work engagement $(p=0.006)$. Age correlated negatively with work engagement $(\mathrm{r}=-0.17, p=0.03)$. No significant differences in the outcome variables were identified for educational level, degree, number of working hours and type of shift work.

\section{Relationships between predictors and outcomes}

The correlations between predictors and outcomes are reported in Table 2. The correlations between predictors were all lower than 0.60 , excluding the risk for multicollinearity.

Hierarchical regression analyses was performed to estimate the strength of the association between personal characteristics (block 1), job characteristics (block 2), organizational variables (block 3) and goal orientation (block 4) on the one hand and work engagement and burnout, on the other hand. The results of the multiple hierarchical regression analyses are reported in Table 3 .

Concerning work engagement, the regression model including only personal characteristics (block 1) explained $8 \%$ of the variance. Female gender was related to higher levels of work engagement. Job characteristics (block 2) added 20\% of explained variance. Job control as well as social support was predictive of work engagement. Organizational variables (block 3) explained an additional 6\% of variance. A more positive perception of reward was related to higher levels of work engagement. Goal orientation (block 4) added an extra 14\% of explained variance. Mastery approach predicted higher levels of work engagement, while performance avoidance had a negative relationship with this outcome variable. The final model explained $47 \%$ (adjusted $41 \%$ ) of the variance in work engagement.

For burnout, the regression model including only personal characteristics was not significantly different from the null model. Job characteristics (block 2) explained $26 \%$ of the variance for burnout. A more positive perception of job demands and job control was related to lower levels of burnout. Organizational variables (block-3) explained an additional $4 \%$ of the variance in psychosomatic distress, but adding this block did not result in a significantly improved regression model. Goal orientation (block-4) added 13\% of explained variance. Mastery approach was related to lower levels of burnout. Performance avoidance was related to higher levels of burnout. The final model explained $46 \%$ (adjusted $41 \%$ ) of the variance.

\section{Discussion}

The present study focused on the relationship between personal characteristics, job characteristics, organizational variables and goal orientation on the one hand and work engagement and burnout on the

Table 1. Personal characteristics of the ER nurses included in this study $(\mathrm{N}=170)$

\begin{tabular}{llr}
\hline Age & Mean (SD) & $38.45(9.18)$ \\
Gender & Female & $58.80 \%$ \\
Nursing degree & Qualified nurse & $11.20 \%$ \\
& Bachelor's degree & $85.90 \%$ \\
& Master's degree & $2.90 \%$ \\
Work schedule & Certified Emergency Nurse' (CEN) certificate & $81.60 \%$ \\
& Changing shifts without night work & $7.40 \%$ \\
Job time & Changing shifts with night work & $87.30 \%$ \\
Job experience as ER nurse & Permanent night shifts & $5.30 \%$ \\
& Part-time (<38 hours/week) & $41.20 \%$ \\
& Fulltime (38 hours/week) & $58.80 \%$ \\
& $<5$ years & $(7.99)$ \\
& $5-10$ years & $27.10 \%$ \\
& $10-15$ years & $20.00 \%$ \\
& $15-20$ years & $21.10 \%$ \\
& $20-25$ years & $15.90 \%$ \\
& $>25$ years & $10.60 \%$ \\
& & $5.30 \%$ \\
\hline
\end{tabular}

SD: standard deviation. 


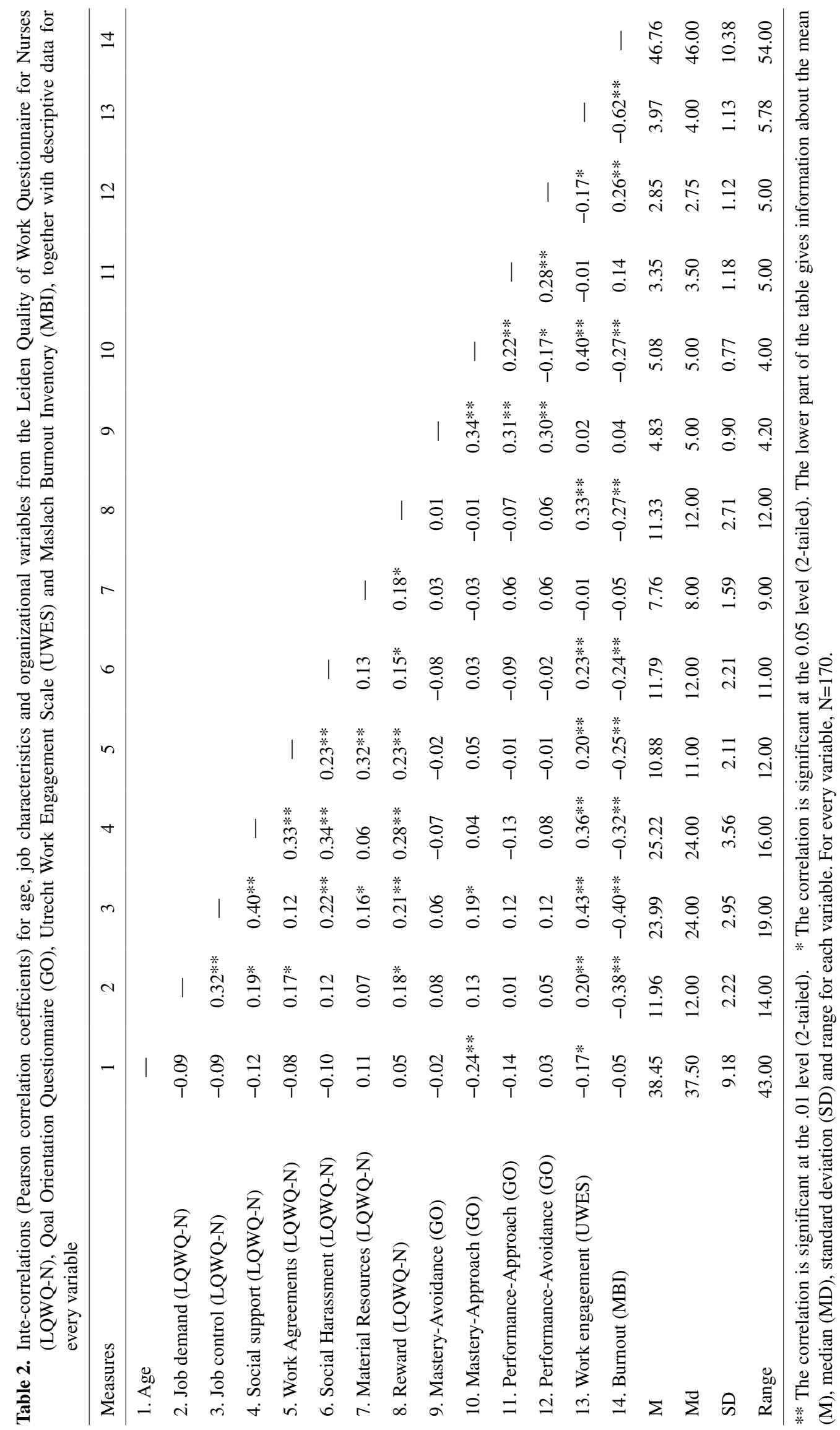


Table 3. Summary of hierarchical regression analysis: personal characteristics (block 1), job characteristics (block 2), organizational variables (block 3) and goal orientation (block 4) as predictors and the sum score for work engagement (UWES) and burnout (MBI) as outcomes

\begin{tabular}{|c|c|c|c|c|}
\hline \multirow[b]{2}{*}{ Predictor } & \multicolumn{2}{|c|}{ Work engagement } & \multicolumn{2}{|c|}{ Burnout } \\
\hline & $\Delta \mathrm{R}^{2}$ & $\beta /$ sign. & $\Delta \mathrm{R}^{2}$ & $\beta /$ sign. \\
\hline Block 1: Personal characteristics & $0.08 *$ & & 0.04 & \\
\hline Gender & & $0.17 *$ & & $-0.16^{*}$ \\
\hline Age & & -0.02 & & $-0.20 * *$ \\
\hline Level of education & & -0.05 & & 0.00 \\
\hline Type of shift work (with(out) night shifts) & & 0.01 & & 0.04 \\
\hline Job time (full time/part time) & & 0.01 & & 0.03 \\
\hline Block 2: Job characteristics & $0.20 * * *$ & & $0.26 * * *$ & \\
\hline Job demands & & 0.01 & & $-0.26 * * *$ \\
\hline Job control & & $0.24 * * *$ & & $-0.24 * * *$ \\
\hline Social support & & $0.17 *$ & & -0.11 \\
\hline Block 3: Organizational variables & $0.06^{*}$ & & 0.04 & \\
\hline Work agreements & & 0.04 & & -0.10 \\
\hline Social harassment & & 0.08 & & -0.09 \\
\hline Material resources & & -0.11 & & 0.07 \\
\hline Reward & & $0.23 * * *$ & & -0.11 \\
\hline Block 4: Goal Orientation & $0.14 * * *$ & & $0.13 * * *$ & \\
\hline Mastery-Avoidance (MAv) & & -0.04 & & 0.02 \\
\hline Mastery-Approach (MAp) & & $0.30^{* * *}$ & & $-0.18^{* *}$ \\
\hline Performance-Approach (PAp) & & 0.01 & & 0.05 \\
\hline \multirow[t]{3}{*}{ Performance-Avoidance (PAv) } & & $-0.20 * *$ & & $0.29 * * *$ \\
\hline & $\mathrm{R}^{2}$ & 0.47 & $\mathrm{R}^{2}$ & 0.46 \\
\hline & Adj. $\mathrm{R}^{2}$ model & $0.41 * * *$ & Adj. $\mathrm{R}^{2}$ model & $0.41 * * *$ \\
\hline
\end{tabular}

$\beta$, beta; $\Delta \mathrm{R}^{2}$, change in explained variance; adj., adjusted. Sign., significance; $* p<0.05 ; * * p \leq 0.01 ; * * * p \leq 0.001$. $\mathrm{N}=170$.

other hand in ER-nurses.

Personal characteristics explained a small part of the variance in work engagement. Women were found to have significantly higher levels of work engagement compared with men. Schaufeli and Bakker ${ }^{35)}$ also found small to moderate gender differences in work engagement but emphasized the lack of practical significance of these findings. Other studies did not find differences between men and women. Further research is needed.

Work characteristics explained a substantive part of the variance in both of the outcome variables. A positive perception of job demands was predictive of lower levels of burnout. High perceived job control was related to higher levels of work engagement and to lower levels of burnout. High perceived social support was related to higher levels of work engagement. Previous cross-sectional and longitudinal studies in (ER) nurses confirm these findings: job characteristics are important predictors of occupational well-being ${ }^{1,37,38)}$. These results are also in line with the Job Demand Resources model ${ }^{39)}$. This model states that working conditions can be categorized in two distinct groups: job demands and job resources. Job demands are the features of the job that require sustained mental or physical effort, while job resources are the aspects of the job that (1) are functional in achieving work goals, (2) reduce the consequences of high job demands and (3) stimulate personal growth and development ${ }^{40)}$. Job control and social support are both considered to be important job resources. Research shows that long-lasting high levels of job demands or chronic depletion of resources are both related to burnout. Moreover, increases in job resources were found to predict work engagement ${ }^{41)}$.

Organizational variables explained a small part of variance in work engagement. A positive perception of reward was associated with higher levels of work engagement. Van der Ploeg and Kleber (2003) did not find any relationship between financial reward and occupational health outcomes in ER nurses ${ }^{42}$. The finding of this study can however be explained by the 
fact that the reward variable of the LQWQ-N instrument measures a broader concept including appreciation and mutual respect.

Goal orientation explained an additional 14 and $13 \%$ of the variance, above work characteristics, organizational and personal characteristics, for work engagement and burnout respectively. The masteryapproach orientation was found to be related to higher levels of work engagement and to lower levels of burnout. This finding is in line with hypothesis 1 . The performance avoidance orientation was inversely related to the outcomes. This finding confirms hypothesis 4 . The emotional states related to these types of goal orientation explain the findings: the mastery-approach orientation is directly related to positive thinking and well-being ${ }^{43}$ and was found to be a predictor of intrinsic motivation, which was in turn negatively related to occupational strain and burnout $^{35)}$. In contrast, avoidant behavior was found to be related to feelings of anxiety and failure, which in turn was predictive of energy depletion, low ability to cope with stress and burnout ${ }^{23,39)}$. More specifically, a performance-avoidance goal orientation proved to be related to low efficacy, high anxiety, less help seeking and use of self-handicapping strategies ${ }^{44}$.

The present study also showed that a performanceapproach goal orientation was not related to any of the outcome variables. Hypothesis 2 was therefore rejected. Several authors found beneficial effects of a performance-approach goal orientation such as persistence, adaptive help seeking and performance attainment. Other researchers found, however, no effects or non-beneficial effects on other outcomes such as depression, emotionality, anxiety and job effectiveness ${ }^{13)}$. It is possible that positive and negative effects cancelled each other out in our study, because we used general outcome measures, such as burnout and work engagement. Finally, the present study showed that the mastery-avoidance orientation was not related to any of the outcome variables. Therefore hypothesis 3 was rejected. In contrast to previous research, the $2 \times 2$ model of goal orientation was thus not supported in this study population ${ }^{23)}$. The masteryavoidance goal orientation is the last addition to the goal orientation literature and is the least studied and understood dimension. Research suggests that the mastery-avoidance goal orientation is rather a hybrid concept, combining the most positive aspect of goal achievement (mastery) with the most negative (avoidance). To date, it is not clear how these two components operate together. In certain situations, the mastery component seems to dominate; in other contexts, the avoidance component seems to be more prominent. On the other hand, in a significant part of the situations, the components cancel each other out.
This might explain that for certain groups, such as elderly, employees who function at the maximum of their capabilities or perfectionists, the mastery-avoidance orientation can be found as a predominant goal orientation, while in other groups, such as emergency nurses, no significant relationships are found ${ }^{45)}$.

The finding that goal orientation explained a substantial additional part of the variance in the outcome variables is important in relation to the occupational well-being of ER nurses. Research shows that an employee's goal orientation can influence the social interaction with the supervisor and the quality of leader-employee exchange ${ }^{13)}$. Employees with a mastery-approach goal orientation have a strong focus on developing competencies and skills. Supervisors are important resources of knowledge and experience for the ER nurse. Good social contacts and adequate information exchange with them are primordial for professional growth to attain work-related goals and to create career opportunities. In contrast, employees with an avoidant goal orientation perceive their supervisors as judges or sources of criticism and negative feedback, leading to fear of failure ${ }^{46)}$. On the other hand, aspects of leadership can influence the goal orientation of the employees. Although goal orientations are seen as rather stable, they can be influenced by contextual and environmental factors ${ }^{13)}$. In order to improve the well-being of employees, management has to build an organizational culture that facilitates the mastery-approach goal orientation ${ }^{13)}$. Adequate social support, constructive feedback and reward systems based on personal involvement and growth, skills development and cooperation can be very beneficial ${ }^{11,13)}$. Finally, the results of the present study suggest a shift in evaluation methods in nursing education and lifelong learning from a performance orientation (with a focus on assessment and examination) towards a mastery orientation (with a focus on active learning, clinical decision-making and internalation of information). Ames ${ }^{11}$ emphasized the need to give students more autonomy in their training process and to evaluate them based on improvement and effort rather than on their relative performance ${ }^{45)}$. Stevens and Gist $^{47)}$ showed that mastery-oriented training was related to more skill-maintenance activities, more positive affect and growth of initially low self-efficacy compared with performance-oriented training.

The relatively large sample of ER nurses compared with other studies, the response rate and the theoretical framework are important strengths of this study. To our knowledge, this study is the first study in ER nurses that includes JDCS characteristics, organizational variables and goal orientation dimensions in relation to occupational well-being. However, due to its cross-sectional design, one has to be cautious when 
attempting to draw conclusions regarding causality. Future longitudinal research is necessary to explore the direction of causality with respect to the findings of this study. Although the response rate of this study was acceptable, more than a third of the eligible respondents did not return the questionnaire, increasing the potential risk of selection bias. Also, due to the sample size of this study, the set of predictors is not exhaustive. Personality characteristics, coping strategies and exposure to traumatic events were also found to be related to burnout and work engagement in previous studies but were not taken into account. Future research has to take these weaknesses into account. In this study, social support was conceptualized as an overarching measure including both social support from colleagues and from a supervisor. Future research should clarify the unique contribution of each of these measures. This study shows that occupational goal orientation is strongly predictive of work engagement and burnout in ER nurses. The authors suggest that future research should explore if the same relationships can also be found in other nursing specialties. Nevertheless, the findings of this study emphasize the need for the creation of a mastery-oriented organizational culture and the facilitation of individual professional growth in order to promote occupational well-being.

Conflict of interests: No conflict of interest has been declared by the authors.

Funding statement: This research received no specific grant from any funding agency in the public, commercial, or not-for-profit sectors.

\section{References}

1) Adriaenssens J, De Gucht V, Maes S. Causes and consequences of occupational stress in emergency nurses, a longitudinal study. J Nurs Manag 2013 [published online ahead of print March 30, 2014] (doi: 10.1111/jonm.12138).

2) Browning L, Ryan C, Thomas S, Greenberg M, Rolniak S. Nursing specialty and burnout. Psychology Health Med 2007; 12: 248-54.

3) Van Beek I, Hu Q, Schaufeli WB, Taris TW, Schreurs BH. For fun, love, or money: what drives workaholic, engaged, and burned-out employees at work? Appl Psychol 2012; 61: 30-55.

4) Van den Broeck A, Van Ruysseveldt J, Smulders P, De Witte $H$. Does intrinsic work value orientation strengthen the impact of job resources? A perspective from the Job Demands-Resources Model. Eur J Work Organ Psy 2011; 20: 581-609.

5) Kalkan M, Odaci H, Epli Koç H. Self-efficacy, coping with stress and goal-orientation in nurse managers. CJES 2011; 3: 118-25.

6) Adie JW, Jowett S. Meta-perceptions of the Coach-
Athlete relationship, achievement goals, and intrinsic motivation among sport participants. J Appl Soc Psychol 2010; 40: 2750-73.

7) Dupeyrat C, Mariné C. Implicit theories of intelligence, goal orientation, cognitive engagement, and achievement: a test of Dweck's model with returning to school adults. Contemp Educ Psychol 2005; 30: 43-59.

8) Retelsdorf J, Butler R, Streblow L, Schiefele U. Teachers' goal orientations for teaching: associations with instructional practices, interest in teaching, and burnout. Learn Instr 2010; 20: 30-46.

9) Naidoo LJ, DeCriscio A, Bily H, Manipella A, Ryan M, Youdim J. The $2 \times 2$ model of goal orientation and burnout: the role of approach-avoidance dimensions in predicting burnout. J Appl Soc Psychol 2012; 42: 2541-63.

10) Parker PD, Martin AJ, Colmae S, Liem GA. Teachers' workplace well-being: exploring a process model of goal orientation, coping behavior, engagement, and burnout. Teach Teach Educ 2012; 28: 503-13.

11) Ames C. Achievement goals, motivational climate, and motivational processes. In: Roberts G, editor. Motivation in sport and exercise. Champaign (IL): Human Kinetic Books; 1992. p. 161-76.

12) Van Yperen N, Janssen O. Fatigued and dissatisfied or fatigued but satisfied? Goal orientations and responses to high job demands. Acad Manage J 2002; 45: 1161-71.

13) Janssen O, Van Yperen N. Employees' goal orientations, the quality of leader-member exchange, and the outcomes of job performance and job satisfaction. Acad Manage J 2004; 47: 368-84.

14) Elliot A, Harackiewicz J. Approach and avoidance achievement goals and intrinsic motivation: a mediational analysis. J Pers Soc Psychol 1996; 70: 461-75.

15) Yeo G, Neal A. A multilevel analysis of effort, practice, and performance: effects of ability, conscientiousness, and goal orientation. J Appl Psychol 2004; 89: 231-47.

16) Kaplan A, Maehr M. The contribution and prospects of goal orientation theory. Educ Psychol Rev 2007; 19: 141-87.

17) Davis W, Carson C, Ammeter A, Treadway D. The interactive effects of goal orientation and feedback specificity on task performance. Hum Perform 2005; 18: 409-26.

18) Ryan A, Pintrich P, Midgley C. Avoiding seeking help in the classroom: who and why? Educ Psychol Rev 2001; 13: 93-114.

19) Darnon C, Muller D, Schrager S, Pannuzzo N, Butera F. Mastery and performance goals predict epistemic and relational conflict regulation. J Educ Psychol 2006; 98: 766-76.

20) Elliot A, Church M. A hierarchical model of approach and avoidance achievement motivation. J Pers Soc Psychol 1997; 72: 218-32.

21) Vandewalle D. Development and validation of a 
work domain goal orientation instrument. Educ Psychol Meas 1997; 57: 995-1015.

22) Baranik L, Barron K, Finney S. Measuring goal orientation in a work domain: construct validity evidence for the $2 \times 2$ framework. Educ Psychol Meas 2007; 67: 697-718.

23) Elliot A. The hierarchical model of approach-avoidance motivation. Motiv Emotion 2006; 30: 111-6.

24) Karasek R, Theorell T. Healthy Work: stress, productivity, and the reconstruction of working life. New York: Basic Books; 1990.

25) Häusser J, Mojzisch A, Niesel M, Schulz-Hardt S. Ten years on: a review of recent research on the Job Demand-Control (-Support) Model and psychological well-being. Work Stress 2010; 24: 1-35.

26) Wagenaar W, Groeneweg J, Hudson P, Reason J. Promoting safety in the oil industry. Ergonomics 1994; 37: 1999-2013.

27) Maslach $C$, Jackson $S$. The measurement of experienced burnout. J Organ Behav 1981; 2: 99-113.

28) Schaufeli W, Bakker A. The conceptualization and measurement of work engagement: A review. In: Bakker A, Leiter M, editors. Work engagement: A handbook of essential theory and research. New York: Psychology Press; 2010.

29) Gelsema T, Pomaki Y, Van der Doef M, Maes S. Goal Orientation and health and wellbeing outcomes in nurses. Leiden (The Netherlands): Health Psychology, Leiden University; 2007.

30) Maes S, Akerboom S, Van der Doef M, Verhoeven C. The Leiden Quality of Work Questionnaire for Nurses. Leiden (The Netherlands): Health Psychology, Leiden University; 1999.

31) Van der Doef M, Maes S. The Leiden Quality of Work Questionnaire: its construction, factor structure, and psychometric qualities. Psychol Rep 1999; 85: 954-62.

32) Schaufeli W, Van Dierendonck D. Burnout, een begrip gemeten. De Nederlandse versie van de Maslach Burnout Inventory (MBI-NL) [BurnoutThe measurement of a concept: The Dutch version of the Maslach Burnout Inventory (MBI-NL)]. Gedrag \& Gezondheid: Tijdschrift voor Psychologie en Gezondheid 1994; 22: 153-72.

33) Ahola K, Toppinen-Tanner S, Huuhtanen P, Oskinen A, äänänen A. Occupational burnout and chronic work disability: an eight year cohort study on pensioning among Finish forest industry workers. J Affect Disord 2009; 115: 150-9.

34) Vanheule S, Rosseel Y, Vlerick P. The factorial validity and measurement invariance of the Maslach
Burnout Inventory for human services. Stress Health 2007; 23: 87-91.

35) Schaufeli W, Bakker A. UWES - Utrecht Work Engagement Scale. Utrecht (The Netherlands): Occupational Health Psychology Unit, Utrecht University; 2004.

36) Seppälä P, Mauno T, Hakanen J, Kinnunen U, Tolvanen A, Schaufeli W. The construct validity of the Utrecht Work Engagement Scale: multisample and longitudinal evidence. J Happiness Stud 2009; 10: 459-81.

37) Khamisa N, Peltzer K, Oldenburg B. Burnout in relation to specific contributing factors and health outcomes among nurse: a systematic review. Int $\mathrm{J}$ Environ Res Public Health 2013; 10: 2214-40.

38) Simpson MR. Engagement at work: a review of the literature. Int J Nurs Stud 2009; 46: 1012-24.

39) Bakker A, Demerouti E. The Job-Demand-Resources model: state of the art. J Manag Psychol 2007; 22: 328.

40) Demerouti E, Bakker A, Nachreiner F, Schaufeli W. The job demands-resources model of burnout. J Appl Psychol 2001; 86: 499-512.

41) Schaufeli W, Bakker A, Van Rhenen W. How changes in job demands and resources predict burnout, work engagement, and sickness absenteeism. J Organ Behav 2009; 30: 893-917.

42) Van der Ploeg E, Kleber RJ. Acute and chronic job stressors among ambulance personnel: predictors of health symptoms. Occup Environ Med 2003; 60 (Suppl 1): i40-6.

43) Coats E, Janoff-Bulman R, Alpert N. Approach versus avoidance goals: differences in self-evaluation and well-being. Pers Soc Psychol B 1996; 22: 1057-67.

44) Urdan T, Ryan A, Anderman E, Gheen M. Goals, goal structures, and avoidance behaviors. In: Midgley C, editor. Goals, goal structures and patterns of adaptive learning. Mahwah (NJ): Lawrence Erlbaum Associates Inc.; 2002. p. 55-81.

45) Elliot A, Dweck C. Handbook of Competence and Motivation. New York: The Guilford Press; 2007. p. 61.

46) Park G, Schmidt A, Scheu C, Deshon R. A process model of goal orientation and feedback seeking. Hum Perform 2007; 20: 119-45.

47) Stevens C, Gist M. Effects of self-efficacy and goal orientation on negotiation skill maintenance: what are the mechanisms? Pers Psychol 1997; 50: 955-78. 